\section{Hospital admissions from birth to early adolescence and early-life risk factors: the 11-year follow-up of the 1993 Pelotas (Brazil) birth cohort study}

\author{
Hospitalizações do nascimento ao início da \\ adolescência e fatores de risco precoces: \\ a visita de 11 anos da coorte de nascimentos \\ de Pelotas, Rio Grande do Sul, Brasil, 1993
}

Ana M. B. Menezes 1 Ricardo B. Noal 1,2 Juraci A. Cesar 2 Pedro C. Hallal 2,3 Cora Luiza Araújo 2,4 Samuel C. Dumith 2 Fernando C. Barros 5 Cesar G. Victora ${ }^{2}$

\title{
Introduction
}

\footnotetext{
1 Programa de Pós-graduação em Epidemiologia Universidade Federal de Pelotas, Pelotas, Brasil. 2 Escola de Saúde, Universidade Católica de Pelotas, Pelotas, Brasil. 3 Programa de Pós-graduação em Educação Física, Universidade Federal de Pelotas, Pelotas, Brasil. ${ }_{4}^{4}$ Faculdade de Nutrição, Universidade Federal de Pelotas, Pelotas, Brasil. 5 Programa de Pós-graduação em Saúde e Comportamento, Universidade Católica de Pelotas, Pelotas, Brasil.

Correspondence A. M. B. Menezes Programa de Pós-graduação em Epidemiologia, Universidade Federal de Pelotas.

Rua Marechal Deodoro 1160, Pelotas, RS 96020-220, Brasil.

anamene@terra.com.br
}

\begin{abstract}
The aim of this prospective analysis was to describe the cumulative incidence of hospital admissions in the first year of life and between 1 and 11 years of age and to explore associated factors. Hospital admissions were collected through regular monitoring in the first year of life, and through maternal report on admissions between 1 and 11 years. Analyses were stratified by sex and adjusted for confounding factors. $18.1 \%$ of children were hospitalized in the first year of life, and 30.7\% between ages 1 and 11 years. Among boys, hospital admission in the first year was associated with low family income, paternal smoking during pregnancy, preterm delivery, and low birthweight. Among girls, in addition to the variables described for boys, black/mixed skin color was also a risk factor for hospital admission. For admissions between 1 and 11 years of age, low family income and gestational age $\geq 37$ weeks were found to be significant risk factors.
\end{abstract}

Hospitalization; Adolescent; Child; Cohort Studies
Data generated by following three birth cohorts in the city of Pelotas, Southern Brazil (1982, 1993, and 2004) documents improvements in a number of maternal and child health indicators. For example, there was a significant decrease in in fant mortality in this period (from 34.6/1,000 live births in 1982 to $19.0 / 1,000$ in 2004) 1 , as well as a more than twofold increase in breastfeeding duration (from 3.1 to 6.8 months in the same period) 2 . However, some important determinants of morbidity have increased in these two decades, including frequency of preterm births (from 6.3\% to $14.7 \%$ ) and low birthweight (from $9 \%$ to $10 \%$ ) 3 . In Brazil, social inequity plays an important role as a determinant of child health, poorer children being more exposed to risk factors and having less access to preventative and curative interventions 4,5 .

Previous publications from the 1982 and 1993 Pelotas cohorts showed that hospitalization in the first year of life is more prevalent among children with low birthweight and lower family income 6,7 . Whereas the major determinants of hospitalization in the first year of life have been well described, there is a lack of studies evaluating hospitalizations throughout childhood and early adolescence. Given that reasons for hospital admission change as a child grows, the determinants of hospitalization are also likely to vary with age 8 . 
The aim of the present study was to describe the cumulative incidence of hospitalizations in the first year of life and between 1 and 11 years of age, and to identify early-life risk factors for these outcomes.

\section{Methods}

We monitored all 5,249 hospital births taken place in the city of Pelotas in 1993. While still in the hospital, all mothers responded to a questionnaire, and all newborn babies were weighed and measured. Subsamples of this population were visited at ages $1,3,6$, and 12 months and 4,6 , and 9 years. In 2004-2005 we carried out a follow-up of all cohort members, the details of which have been published elsewhere 9 .

The outcome of the present analysis - hospitalization - was defined as a stay in a hospital lasting longer than 24 hours. Data sources differed for the different age ranges studied. For hospitalizations in the first year of life, a team visited the city's five hospitals on a daily basis, inquiring whether any child born in 1993 had been hospitalized that day. Information on hospitalizations between ages 1 and 11 years were obtained during the 2004-2005, when we asked mothers visit whether their child had ever been hospitalized. In case of a positive answer, we also obtained information on the number of times the child had been hospitalized, from which we subtracted the number of hospitalizations in the first year of life. For the analyses in the present study, we disregarded the number of hospitalizations, creating a dichotomous variable (yes/no) for the outcome, which did not require any adjustment due to the absence of independence between the two measures.

Independent variables investigated included self-reported skin color (white, black/mixed), family income in minimum wages at birth (> 10.0; 6.1-10.0; 3.1-6.0; 1.1-3.0; $\leq 1.0$ ), maternal and paternal smoking during pregnancy (yes/ no), gestational age ( $\geq 37 ;<37$ weeks), low birthweight $(<2,500 \mathrm{~g})$, total duration of breastfeeding in months $(\geq 12.0 ; 9-11.9 ; 6-8.9 ; 3-5.9 ; 1-2.9$; $0-0.9$ ), and smoking in the household on occasion of the child's first birthday. Given the difference in mean birthweight between boys and girls, we chose to analyze data stratified by sex, using percentile 10 for defining low birthweight $(<2,570$ g for boys and $<2,480 \mathrm{~g}$ for girls). Breastfeeding and smoking in the household when the child was one year old were not studied in relation to hospitalizations during the first year of life due to the impossibility to establish a temporal relationship between these events.
All independent variables were collected for all children during the postnatal interview, with two exceptions. Duration of breastfeeding and smoking in the household in 1994 were collected during the one year follow-up, which included all low-birthweight children plus $20 \%$ of the remaining children. Analyses that included these variables were weighted to compensate for the oversampling of low birthweight children.

We analyzed data using the Stata 9.2 statistical package (Stata Corp., College Station, USA). We initially described the cumulative incidence of the outcome with its respective 95\% confidence intervals $(95 \% \mathrm{CI})$ for the two studied age groups and later carried out crude and adjusted analysis (cumulative incidence ratio), stratified by sex. We used the chi-squared and Wald tests for heterogeneity and linear trend.

Analyses were adjusted for confounders according to a hierarchical model which included skin color and family income in its first level and maternal and paternal smoking during pregnancy, gestational age, and low birthweight in its second level. Given the smaller number of observations, breastfeeding and smoking in the household in 1994 were included in the third determination level, which allowed us to maintain practically the entire sample in the multilevel analysis up to the second level.

The present study was approved by the Research Ethics Committee of the School of Medicine, Federal University in Pelotas. Parents or caretakers signed a term of free informed consent authorizing the youth to participate in the study.

\section{Results}

The percentage of children hospitalized from ages 0 to 1 and 1 to 11 years was $18.1 \%$ (95\%CI: 15.7 ; 20.5) and 30.7 (95\%CI: 28.5; 33.5), respectively. Boys were more frequently hospitalized than girls $(18.4 \%$ vs. $16.1 \%$ in the first year and $33.9 \%$ vs. $27.4 \%$ in the next 10 years). Cause of hospitalization was collected only for events taken place in the first year of life and in the 12 months preceding the 2004-2005 interview. In the latter period, 87 adolescents were hospitalized ( $2 \%$ of subjects). In the first year, there was a predominance of hospitalizations from infectious diseases (19.6\% from respiratory infections, $14.8 \%$ from gastrointestinal infections, $9.7 \%$ from acute bronchitis, $5 \%$ due to preterm birth, and the remaining due to other causes). On the other hand, reasons for hospitalization at age 10-11 years were more varied: 15 from respiratory disease (especially bronchial asthma), 15 from di- 
gestive problems (abdominal hernias, appendicitis, etc.); 12 for carrying out complex laboratory investigations, and 6 from external causes. The remaining hospitalizations were due to a large number of distinct causes.

Among mothers who claimed their children had not been hospitalized in the first year of life, $93.1 \%$ were correct according to data collected between the child's birth and first birthday (negative predictive value). The negative predictive value was directly associated with the assets in$\operatorname{dex}(89.5 \%$ in the poorest quintile and $96 \%$ in the richest).

Table 1 shows that hospitalizations in the first year were more frequent among children of black/mixed skin, whose family income was

Table 1

Cumulative incidence of hospitalization in and after the first year of life. 1993 Pelotas (Brazil) birth cohort, 2004-2005 follow-up

\begin{tabular}{|c|c|c|c|c|}
\hline \multirow[t]{3}{*}{ Variables } & \multicolumn{4}{|c|}{ Hospitalizations } \\
\hline & \multicolumn{2}{|c|}{$0-1$ year } & \multicolumn{2}{|c|}{$1-11$ years } \\
\hline & $\begin{array}{l}\text { Incidence } \\
\text { (per 100) }\end{array}$ & $\mathrm{p}$-value & $\begin{array}{l}\text { Incidence } \\
\text { (per 100) }\end{array}$ & $\mathrm{p}$-value \\
\hline Sex * & & 0.040 * & & $<0.001$ \\
\hline Female & 16.1 & & 27.1 & \\
\hline Male & 18.4 & & 34.4 & \\
\hline Self-reported skin color * & & $<0.001$ & & 0.421 \\
\hline White & 15.3 & & 30.0 & \\
\hline Black/Mixed & 21.7 & & 31.3 & \\
\hline Family income in 1993 (minimum wages) ** & & $<0.001$ & & 0.003 \\
\hline$>10.0$ & 7.5 & & 25.1 & \\
\hline $6.1-10.0$ & 10.2 & & 27.4 & \\
\hline $3.1-6.0$ & 15.8 & & 29.9 & \\
\hline $1.1-3.0$ & 20.4 & & 31.8 & \\
\hline$\leq 1.0$ & 23.7 & & 32.6 & \\
\hline Mother smoked during pregnancy * & & 0.001 & & 0.255 \\
\hline No & 16.8 & & 30.2 & \\
\hline Yes & 20.7 & & 31.8 & \\
\hline Paternal smoking during pregnancy * & & $<0.001$ & & 0.848 \\
\hline No & 16.4 & & 30.8 & \\
\hline Yes & 20.2 & & 30.5 & \\
\hline Gestational age (weeks) * & & $<0.001$ & & 0.096 \\
\hline$\geq 37$ & 15.3 & & 31.0 & \\
\hline$<37$ & 40.8 & & 27.3 & \\
\hline Low birthweight * & & $<0.001$ & & 0.997 \\
\hline No & 15.2 & & 30.6 & \\
\hline Yes & 45.3 & & 30.7 & \\
\hline 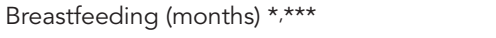 & & & & 0.014 \\
\hline$\geq 12.0$ & & & 15.6 & \\
\hline $9.0-11.9$ & & & 4.0 & \\
\hline $6.0-8.9$ & & & 10.0 & \\
\hline 3.0-5.9 & & & 27.9 & \\
\hline $1.0-2.9$ & & & 27.8 & \\
\hline $0.0-0.9$ & & & 14.8 & \\
\hline 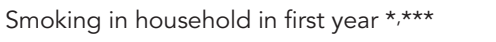 & & & & 0.388 \\
\hline No & & & 27.9 & \\
\hline Yes & & & 30.4 & \\
\hline
\end{tabular}

* Chi-squared test for heterogeneity;

** Chi-squared test for linear trend;

$\star \star \star$ Weighted analysis. 
equal to or lower than one minimum wage, whose mother and father smoked during pregnancy, and who were preterm and low birthweight. Low family income was associated with hospitalization between 1 and 11 years of age. Shorter duration of predominant breastfeeding was also significantly associated with hospitalization after the first year, but did not show a dose-response effect; intermediate breastfeeding categories (1.0-2.9 and 3.0-5.9 months) showed the highest incidence of hospitalization $(27.8 \%$ and $27.9 \%)$, respectively $(\mathrm{p}=0.005)$.

Given the small number of hospitalizations during the 12 months preceding the 2004-2005 interview, we were unable to carry out more detailed analyses of this outcome. It is worth noting, however, that these were more frequent among boys ( $2.7 \%$ of the sample) than among girls $(1.3 \%)$.
Crude and adjusted analysis of hospitalizations among boys during the first year of life (Table 2) showed that low family income, paternal smoking during pregnancy, preterm birth, and low birthweight remained significant risk factors even after confounder control. The association with black/mixed skin lost statistical significance in adjusted analysis, even though it led to a $20 \%$ increase in risk of hospitalization at this age $(\mathrm{p}=0.06)$.

The same variables were associated with hospitalization among girls (Table 3), in addition to black/mixed skin color, which was also significantly associated with hospitalization. Maternal smoking during pregnancy, which was associated with the outcome in crude analysis, lost statistical significance after adjustment.

The results of the crude analysis of hospitalizations among boys at age 1-11 years remained

Crude and adjusted analysis of the effects of independent variables on hospitalization in the first year of life, among boys. 1993 Pelotas (Brazil) birth cohort, 2004-2005 follow-up.

\begin{tabular}{|c|c|c|c|c|c|c|}
\hline \multirow[t]{2}{*}{ Variables } & \multicolumn{3}{|c|}{ Crude analysis } & \multicolumn{3}{|c|}{ Adjusted analysis * } \\
\hline & $\begin{array}{c}\text { Cumulative } \\
\text { incidence ratio }\end{array}$ & $95 \% \mathrm{Cl}$ & $\mathrm{p}$-value & $\begin{array}{c}\text { Cumulative } \\
\text { incidence ratio }\end{array}$ & $95 \% \mathrm{Cl}$ & p-value \\
\hline \multicolumn{7}{|l|}{ First level } \\
\hline Skin color ** & & & 0.005 & & & 0.063 \\
\hline White & 1.00 & & & 1.00 & & \\
\hline Black/Mixed & 1.31 & $1.09 ; 1.59$ & & 1.20 & $0.99 ; 1.45$ & \\
\hline Family income in 1993 (minimum wages) *** & & & $<0.001$ & & & $<0.001$ \\
\hline$>10.0$ & 1.00 & & & 1.00 & & \\
\hline $6.1-10.0$ & 1.29 & $0.66 ; 2.55$ & & 1.38 & $0.69 ; 2.76$ & \\
\hline $3.1-6.0$ & 1.85 & $1.05 ; 3.23$ & & 1.90 & $1.06 ; 3.40$ & \\
\hline $1.1-3.0$ & 2.52 & $2.48 ; 4.31$ & & 2.57 & $1.47 ; 4.51$ & \\
\hline$\leq 1.0$ & 2.95 & $1.71 ; 5.12$ & & 2.94 & $1.66 ; 5.24$ & \\
\hline \multicolumn{7}{|l|}{ Second level } \\
\hline Mother smoked during pregnancy ** & & & 0.042 & & & 0.961 \\
\hline No & 1.00 & & & 1.00 & & \\
\hline Yes & 1.21 & $1.01 ; 1.45$ & & 1.00 & $0.83 ; 1.21$ & \\
\hline Father smoked during pregnancy ** & & & 0.007 & & & 0.033 \\
\hline No & 1.00 & & & 1.00 & & \\
\hline Yes & 1.27 & $1.07 ; 1.52$ & & 1.21 & $1.01 ; 1.43$ & \\
\hline Gestational age (weeks) ** & & & $<0.001$ & & & $<0.001$ \\
\hline$\geq 37$ & 1.00 & & & 1.00 & & \\
\hline$<37$ & 2.65 & $2.20 ; 3.19$ & & 1.85 & $1.48 ; 2.31$ & \\
\hline Low birthweight $(<2,570 \mathrm{~g}) * \star$ & & & $<0.001$ & & & $<0.001$ \\
\hline No & 1.00 & & & 1.00 & & \\
\hline Yes & 2.84 & $2.37 ; 3.41$ & & 2.00 & $1.60 ; 2.49$ & \\
\hline
\end{tabular}

* Adjusted analysis: the effect of each exposure on the outcome was adjusted for variables in the same or in a higher level;

** Wald's test for heterogeneity;

$\star \star \star$ Wald's test for linear trend. 
Crude and adjusted analysis of the effects of independent variables on hospitalization in the first year of life, among girls. 1993 Pelotas (Brazil) birth cohort, 2004-2005 follow-up.

\begin{tabular}{|c|c|c|c|c|c|c|}
\hline \multirow[t]{2}{*}{ Variables } & \multicolumn{3}{|c|}{ Crude analysis } & \multicolumn{3}{|c|}{ Adjusted analysis * } \\
\hline & $\begin{array}{l}\text { Cumulative } \\
\text { incidence ratio }\end{array}$ & $95 \% \mathrm{Cl}$ & $p$-value & $\begin{array}{l}\text { Cumulative } \\
\text { incidence ratio }\end{array}$ & $95 \% \mathrm{Cl}$ & p-value \\
\hline \multicolumn{7}{|l|}{ First level } \\
\hline Skin color ** & & & $<0.001$ & & & $<0.001$ \\
\hline White & 1.00 & & & 1.00 & & \\
\hline Black/Mixed & 1.56 & $1.28 ; 1.89$ & & 1.45 & $1.19 ; 1.77$ & \\
\hline Family income in 1993 (minimum wages) *** & & & $<0.001$ & & & $<0.001$ \\
\hline$>10.0$ & 1.00 & & & 1.00 & & \\
\hline $6.1-10.0$ & 1.26 & $0.60 ; 2.66$ & & 1.21 & $0.57 ; 2.55$ & \\
\hline $3.1-6.0$ & 2.28 & $1.25 ; 4.16$ & & 2.09 & 1.14. 3.81 & \\
\hline $1.1-3.0$ & 2.51 & $1.40 ; 4.51$ & & 2.25 & $1.25 ; 4.05$ & \\
\hline$\leq 1.0$ & 2.75 & $1.51 ; 5.03$ & & 2.40 & $1.31 ; 4.42$ & \\
\hline \multicolumn{7}{|l|}{ Second level } \\
\hline Mother smoked during pregnancy ** & & & 0.008 & & & 0.470 \\
\hline No & 1.00 & & & 1.00 & & \\
\hline Yes & 1.29 & $1.07 ; 1.56$ & & 1.08 & $0.88 ; 1.33$ & \\
\hline Father smoked during pregnancy ** & & & 0.063 & & & 0.290 \\
\hline No & 1.00 & & & 1.00 & & \\
\hline Yes & 1.20 & $0.99 ; 1.56$ & & 1.11 & $0.92 ; 1.33$ & \\
\hline Gestational age (weeks) ** & & & $<0.001$ & & & $<0.001$ \\
\hline$\geq 37$ & 1.00 & & & 1.00 & & \\
\hline$<37$ & 2.73 & $2.24 ; 3.32$ & & 1.72 & $1.35 ; 2.19$ & \\
\hline 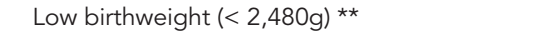 & & & $<0.001$ & & & $<0.001$ \\
\hline No & 1.00 & & & 1.00 & & \\
\hline Yes & 3.10 & $2.56 ; 3.76$ & & 2.20 & $1.73 ; 2.80$ & \\
\hline
\end{tabular}

*Adjusted analysis: the effect of each exposure on the outcome was adjusted for variables in the same or in a higher level;

** Wald's test for heterogeneity;

$\star \star \star$ Wald's test for linear trend.

after adjustment, i.e., only low income and gestational age $\geq 37$ weeks were significantly associated with the outcome (Table 4). Among girls (Table 5), none of the variables investigated was significantly associated with hospitalization between ages 1 and 11 years.

\section{Discussion}

Studies of hospitalizations among children and adolescents are useful for identifying determinants, which can guide the adoption of preventative measures aimed at reducing its prevalence. In middle-income countries such as Brazil, there is a relative scarcity of prospective cohort studies with medium to long-term follow up - which allow one to describe the occurrence of hospitalizations and its risk factors throughout the life cycle 10 .
In the present study, hospitalization in the first year of life was monitored by the study team, thus avoiding recall bias. However, hospitalization between ages 1 and 11 years was reported by the mother at age 11, and may have been underestimated. We do not have direct data on the potential magnitude of underestimation for the 1-11 age group, though, as shown above, $6.8 \%$ of mothers who in 2004-2005 reported that their children had never been admitted to the hospital were wrong, since the monitoring system had detected the hospitalization of these children during their first year of life.

Low family income was directly associated with hospitalizations in the first year, showing a dose-response trend. This is in agreement with previous studies carried out in Pelotas ${ }^{6}$. Infections are the major cause of hospitalization at this age, and poor children, in addition to being more exposed to environmental hazards, 
Crude and adjusted analysis of the effects of independent variables on hospitalization after the first year of life, among boys. 1993 Pelotas (Brazil) birth cohort, 2004-2005 follow-up.

\begin{tabular}{|c|c|c|c|c|c|c|}
\hline \multirow[t]{2}{*}{ Variables } & \multicolumn{3}{|c|}{ Crude analysis } & \multicolumn{3}{|c|}{ Adjusted analysis * } \\
\hline & $\begin{array}{c}\text { Cumulative } \\
\text { incidence ratio }\end{array}$ & $95 \% \mathrm{Cl}$ & p-value & $\begin{array}{c}\text { Cumulative } \\
\text { incidence ratio }\end{array}$ & $95 \% \mathrm{Cl}$ & p-value \\
\hline \multicolumn{7}{|l|}{ First level } \\
\hline Skin color ** & & & 0.505 & & & 0.937 \\
\hline White & 1.00 & & & 1.00 & & \\
\hline Black/Mixed & 1.05 & $0.92 ; 1.19$ & & 1.00 & $0.88 ; 1.15$ & \\
\hline Family income in 1993 (minimum wages) *** & & & 0.004 & & & 0.004 \\
\hline$>10.0$ & 1.00 & & & 1.00 & & \\
\hline $6.1-10.0$ & 1.28 & $0.89 ; 1.84$ & & 1.28 & $0.89 ; 1.84$ & \\
\hline $3.1-6.0$ & 1.51 & $1.11 ; 2.05$ & & 1.51 & $1.11 ; 2.05$ & \\
\hline $1.1-3.0$ & 1.47 & $1.09 ; 1.97$ & & 1.47 & $1.09 ; 1.97$ & \\
\hline$\leq 1.0$ & 1.59 & $1.17 ; 2.17$ & & 1.59 & $1.17 ; 2.17$ & \\
\hline \multicolumn{7}{|l|}{ Second level } \\
\hline Mother smoked during pregnancy ** & & & 0.067 & & & 0.088 \\
\hline No & 1.00 & & & 1.00 & & \\
\hline Yes & 1.12 & $0.99 ; 1.26$ & & 1.11 & $0.98 ; 1.26$ & \\
\hline Father smoked during pregnancy ** & & & 0.728 & & & \\
\hline No & 1.00 & & & 1.00 & & 0.867 \\
\hline Yes & 1.02 & $0.91 ; 1.15$ & & 0.99 & $0.88 ; 1.12$ & \\
\hline Gestational age $\left(\right.$ weeks) ${ }^{\star \star}$ & & & 0.044 & & & 0.014 \\
\hline$\geq 37$ & 1.00 & & & 1.00 & & \\
\hline$<37$ & 0.80 & $0.64 ; 0.99$ & & 0.73 & $0.57 ; 0.94$ & \\
\hline Low birthweight $(<2,570 \mathrm{~g})$ ** & & & 0.813 & & & 0.194 \\
\hline No & 1.00 & & & 1.00 & & \\
\hline Yes & 1.02 & $0.84 ; 1.24$ & & 1.15 & $0.93 ; 1.43$ & \\
\hline \multicolumn{7}{|l|}{ Third level } \\
\hline Breastfeeding (months) ***,\# & & & 0.210 & & & 0.303 \\
\hline$\geq 12.0$ & 1.00 & & & 1.00 & & \\
\hline $9.0-11.9$ & 1.02 & $0.48 ; 2.19$ & & 1.06 & $0.48 ; 2.32$ & \\
\hline $6.0-8.9$ & 1.72 & $1.04 ; 2.85$ & & 1.61 & $0.98 ; 2.66$ & \\
\hline $3.0-5.9$ & 1.68 & $1.11 ; 2.53$ & & 1.61 & $1.06 ; 2.45$ & \\
\hline $1.0-2.9$ & 1.34 & $0.87 ; 2.04$ & & 1.22 & $0.79 ; 1.88$ & \\
\hline $0.0-0.9$ & 1.31 & $0.83 ; 2.07$ & & 1.30 & $0.83 ; 2.05$ & \\
\hline Smoking in household in first year **,\# & & & 0.231 & & & 0.221 \\
\hline No & 1.00 & & & 1.00 & & \\
\hline Yes & 1.16 & $0.91 ; 1.49$ & & 1.18 & $0.91 ; 1.52$ & \\
\hline
\end{tabular}

* Adjusted analysis: the effect of each exposure on the outcome was adjusted for variables in the same or in a higher level;

** Wald's test for heterogeneity;

$\star \star \star$ Wald's test for linear trend;

\# Weighted.

are also less covered by preventative interventions and have less access to laboratory tests and drugs that could potentially prevent hospitalization. Interviews with local physicians suggest that hospitalization is a frequent strategy used to ensure access to diagnostic and therapeutic procedures among poor children, since these procedures are not always readily available at the outpatient level. The same inverse association with family income was found for hospitalizations between ages 1 and 11 among boys, though the magnitude of this risk was lower than that of hospitalization in the first year. Although there was a similar trend with regard to income among girls, this association was not statistically significant. 
Table 5

Crude and adjusted analysis of the effects of independent variables on hospitalization after the first year of life, among girls. 1993 Pelotas (Brazil) birth cohort, 2004-2005 follow-up.

\begin{tabular}{|c|c|c|c|c|c|c|}
\hline \multirow[t]{2}{*}{ Variables } & \multicolumn{3}{|c|}{ Crude analysis } & \multicolumn{3}{|c|}{ Adjusted analysis * } \\
\hline & $\begin{array}{c}\text { Cumulative } \\
\text { incidence ratio }\end{array}$ & $95 \% \mathrm{Cl}$ & p-value & $\begin{array}{c}\text { Cumulative } \\
\text { incidence ratio }\end{array}$ & $95 \% \mathrm{Cl}$ & p-value \\
\hline \multicolumn{7}{|l|}{ First level } \\
\hline Skin color ** & & & 0.458 & & & 0.576 \\
\hline White & 1.00 & & & 1.00 & & \\
\hline Black/Mixed & 1.06 & $0.91 ; 1.23$ & & 1.05 & $0.90 ; 1.22$ & \\
\hline Family income in 1993 (minimum wages) *** & & & 0.208 & & & 0.208 \\
\hline$>10.0$ & 1.00 & & & 1.00 & & \\
\hline $6.1-10.0$ & 0.92 & $0.93 ; 1.92$ & & 0.92 & $0.93 ; 1.92$ & \\
\hline $3.1-6.0$ & 0.92 & $1.08 ; 2.00$ & & 0.92 & $1.08 ; 2.00$ & \\
\hline $1.1-3.0$ & 1.09 & $1.07 ; 1.94$ & & 1.09 & $1.07 ; 1.94$ & \\
\hline$\leq 1.0$ & 1.05 & $1.22 ; 2.26$ & & 1.05 & $1.22 ; 2.26$ & \\
\hline \multicolumn{7}{|l|}{ Second level } \\
\hline Mother smoked during pregnancy ** & & & 0.928 & & & 0.931 \\
\hline No & 1.00 & & & 1.00 & & \\
\hline Yes & 0.99 & $0.86 ; 1.15$ & & 1.01 & $0.87 ; 1.17$ & \\
\hline Father smoked during pregnancy ** & & & 0.583 & & & 0.630 \\
\hline No & 1.00 & & & 1.00 & & \\
\hline Yes & 0.96 & $0.84 ; 1.10$ & & 0.97 & $0.84 ; 1.11$ & \\
\hline Gestational age (weeks) ${ }^{\star \star}$ & & & 0.893 & & & 0.893 \\
\hline$\geq 37$ & 1.00 & & & 1.00 & & \\
\hline$<37$ & 0.99 & $0.79 ; 1.22$ & & 0.99 & $0.79 ; 1.22$ & \\
\hline Low birthweight $(<2,480 \mathrm{~g})$ ** & & & 0.928 & & & 0.968 \\
\hline No & 1.00 & & & 1.00 & & \\
\hline Yes & 0.99 & $0.79 ; 1.24$ & & 0.99 & $0.76 ; 1.30$ & \\
\hline \multicolumn{7}{|l|}{ Third level } \\
\hline Breastfeeding (months) $* \star \star, \#$ & & & 0.090 & & & 0.090 \\
\hline$\geq 12.0$ & 1.00 & & & 1.00 & & \\
\hline $9.0-11.9$ & 1.21 & $0.54 ; 2.70$ & & 1.21 & $0.54 ; 2.70$ & \\
\hline $6.0-8.9$ & 1.89 & $1.06 ; 3.39$ & & 1.89 & $1.06 ; 3.39$ & \\
\hline $3.0-5.9$ & 1.50 & $0.94 ; 2.39$ & & 1.50 & $0.94 ; 2.39$ & \\
\hline $1.0-2.9$ & 1.80 & $1.16 ; 2.82$ & & 1.80 & $1.16 ; 2.82$ & \\
\hline $0.0-0.9$ & 1.14 & $0.66 ; 1.99$ & & 1.14 & $0.66 ; 1.99$ & \\
\hline Smoking in household in first year **,\# & & & 0.926 & & & 0.856 \\
\hline No & 1.00 & & & 1.00 & & \\
\hline Yes & 0.99 & $0.73 ; 1.34$ & & 0.97 & $0.72 ; 1.32$ & \\
\hline
\end{tabular}

* Adjusted analysis: the effect of each exposure on the outcome was adjusted for variables in the same or in a higher level;

** Wald's test for heterogeneity;

$\star \star \star$ Wald's test for linear trend;

\# Weighted.

The present study was carried out in an urban setting, where availability of primary, secondary, and tertiary healthcare services under the Unified National Health System (SUS) is high. There were therefore no economic barriers to access to hospital admission. Studies from other lowand middle-income countries show a different pattern, with important barriers preventing the access of poorer and rural populations to hospitalization. Our results must therefore not be extrapolated to these other contexts.

Childhood morbidity is generally higher among boys 11, which is in agreement with our finding that hospitalizations are more frequent 
among boys in both age groups studied. A survey of hospitalizations from respiratory infections carried out in Denmark showed that, between age 15 and 25 years, risk of hospitalization is higher among females 11.

Although there are reports in the literature of an association between smoking during pregnancy and hospitalizations from various causes $12,13,14$, our data show such an association only for boys hospitalized between 0 and 1 year of age, and related to paternal and not maternal smoking. Likewise, although there is a reported association between preterm birth and hospitalization in the first five years of life 15 , adolescence, and early adulthood 16 , in our cohort this association was true only for hospitalization during the first year. On the contrary, we detected a significant association between gestational age $\geq 37$ weeks and later hospitalizations among boys. There is no clear explanation for this finding, which deserves further investigation.

Low birthweight was a risk factor for hospitalizations between birth and 1 year of age. A population-based cohort study from Denmark showed an inverse association between birthweight and risk of hospitalization from infectious diseases between ages 0 and 14 years, with a $9 \%$ increase in risk of hospitalization for every $500 \mathrm{~g}$ reduction in birthweight 17. In our cohort, such an association was not evident for later hospitalization. A possible explanation for this finding is the fact that our study, unlike the Danish one, excluded from the analysis of late hospitalizations all instances taken place during the first year of life.

The protection offered by breastfeeding against infant morbidity (especially related to infectious disease) has been thoroughly demonstrated in the literature $18,19,20,21$. In our cohort, however, since we collected data on breastfeeding only at the age of 12 months, we were unable to test this association given the possibility of reverse causality bias - i.e., that hospitalization may have interrupted breastfeeding. There was no association between breastfeeding and later hospitalization.

Hospitalizations are an important indicator of severe morbidity and should be monitored in all age groups. The present study shows, in agreement with the international literature, that hospitalizations during the first year of life among both boys and girls are strongly associated with well known risk factors such as poverty, preterm birth, and low birthweight 22,23. The influence of early factors on hospitalization between ages 1 and 11 , however, is less evident, given the variety of causes to which the latter is associated.

\section{Resumo}

Com o objetivo de descrever a incidência cumulativa de hospitalizações no primeiro ano de vida e entre 1-11 anos de idade, e identificar fatores de risco precoces, foi realizado um estudo de coorte de nascimento de 1993 a 2004-2005. As hospitalizações foram coletadas por meio de monitoramento hospitalar até 1 ano de idade, e relato das mães sobre internações ocorridas de 1-11 anos. As análises foram estratificadas por sexo e ajustadas para fatores de confusão. Os percentuais de hospitalizações de 0-1 ano e de 1-11 anos foram 18,1\%

e 30,7\%, respectivamente. As variáveis associadas com internações de 0-1 ano em meninos foram: baixa renda familiar, tabagismo paterno na gestação, prematuridade e baixo peso ao nascer. No sexo feminino, além dos fatores de risco descritos entre os meninos, observou-se associação com cor da pele preta/parda. Quanto às hospitalizações de 1-11 anos, no sexo masculino, encontrou-se associação com baixa renda familiar $e$ idade gestacional $\geq 37$ semanas.

Hospitalização; Adolescente; Criança; Estudos de Coortes 


\section{Contributors}

A. M. B. Menezes and C. L. Araújo collaborated in project coordination, data collection, and with the writing of the manuscript. R. B. Noal participated in data collection and analysis and in writing the manuscript. J. A. Cesar participated in the approval of the final version of the manuscript. P. C. Hallal contributed to project coordination, data collection, statistical analysis, and to the writing of the manuscript. F. C. Barros collaborated in project coordination and in writing the manuscript. C. G. Victora contributed to project coordination, data collection and analysis, and in writing the manuscript.

\section{Acknowledgments}

The cohort study is supported by the Wellcome Trust. The initial phases of the cohort study were funded by the European Union, the Brazilian National Program for Centers of Excellence (PRONEX), the National Research Council (CNPq), and the Brazilian Ministry of Health.

\section{References}

1. Matijasevich A, Victora CG, Barros AJ, Santos IS, Marco PL, Albernaz EP, et al. Widening ethnic disparities in infant mortality in southern Brazil: comparison of 3 birth cohorts. Am J Public Health 2008; 98:692-8.

2. Victora CG, Matijasevich A, Santos IS, Barros AJD, Horta BL, Barros FC. Breastfeeding and feeding patterns in three birth cohorts in Southern Brazil: trends and differentials. Cad Saúde Pública 2008; 24 Suppl 3: S409-16.

3. Barros FC, Victora CG, Matijasevich A, Santos IS, Horta BL, Silveira MF, et al. Preterm births, low birthweight, and intrauterine restriction in three birth cohorts in Southern Brazil: 1982, 1993 and 2004. Cad Saúde Pública 2008; 24 Suppl 3: S390-8.

4. Aerts D, Drachler ML, Giugliani ERJ. Determinants of growth retardation in Southern Brazil. Cad Saúde Pública 2004; 20:1182-90.
5. Andrade IG, Queiroz JW, Cabral AP, Lieberman JA Jeronimo SM. Improved sanitation and income are associated with decreased rates of hospitalization for diarrhoea in Brazilian infants. Trans R Soc Trop Med Hyg 2009; 103:506-11.

6. Cesar JA, Matijasevich A, Santos IS, Barros AJD, Dias-da-Costa JS, Barros FC, et al. The use of maternal and child health services in three population-based cohorts in Southern Brazil, 1982-2004. Cad Saúde Pública 2008; 24 Suppl 3:S427-36.

7. Cesar JA, Victora CG, Barros FC, Ramos FA, Albernaz EP, Oliveira LM, et al. Hospitalizações em menores de um ano pertencentes a duas coortes de base populacional no Sul do Brasil: tendências e diferenciais. Cad Saúde Pública 1996; 12 Suppl 1:67-71.

8. Chen E, Martin AD, Matthews KA. Trajectories of socioeconomic status across children's lifetime predict health. Pediatrics 2007; 120:e297-303. 
9. Araújo CL, Menezes AMB, Vieira MFA, Neutzling MB, Gonçalves H, Anselmi L, et al. The 11-year follow-up of the 1993 Pelotas (Brazil) birth cohort study: methods. Cad Saúde Pública 2010; 26: 1875-86.

10. Victora CG. What's the denominator? Lancet 1993; 342:97-9.

11. Jensen-Fangel S, Mohey R, Johnsen SP, Andersen PL, Sorensen HT, Ostergaard L. Gender differences in hospitalization rates for respiratory tract infections in Danish youth. Scand J Infect Dis 2004; 36:31-6.

12. Dombrowski SC, Martin RP, Huttunen MO. Gestational exposure to cigarette smoke imperils the long-term physical and mental health of offspring. Birth Defects Res A Clin Mol Teratol 2005; 73:170-6.

13. Kukla L, Hruba D, Tyrlik M. Influence of prenatal and postnatal exposure to passive smoking on infants' health during the first six months of their life. Cent Eur J Public Health 2004; 12:157-60.

14. Suzuki M, Thiem VD, Yanai H, Matsubayashi T, Yoshida LM, Tho LH, et al. Association of environmental tobacco smoking exposure with an increased risk of hospital admissions for pneumonia in children under 5 years of age in Vietnam. Thorax 2009; 64:484-9.

15. Clark JE, Hammal D, Hampton F, Spencer D, Parker L. Epidemiology of community-acquired pneumonia in children seen in hospital. Epidemiol Infect 2007; 135:262-9.

16. Selling KE, Carstensen J, Finnström O, Josefsson A, Sydsjö G. Hospitalizations in adolescence and early adulthood among Swedish men and women born preterm or small for gestational age. Epidemiology 2008; 19:63-70.
17. Hviid A, Melbye M. The impact of birth weight on infectious disease hospitalization in childhood. Am J Epidemiol 2007; 165:756-61.

18. Cesar JA, Victora CG, Barros FC, Santos IS, Flores JA. Impact of breast feeding on admission for pneumonia during postneonatal period in Brazil: nested case-control study. BMJ 1999; 318:1316-20.

19. Paricio-Talayero JM, Lizán-García M, Otero-Puime A, Benlloch-Muncharaz MJ, Beseler-Soto B, Sánchez-Palomares M, et al. Full breastfeeding and hospitalization as a result of infections in the first year of life. Pediatrics 2006; 118:e92-9.

20. Quigley MA, Kelly YJ, Sacker A. Breastfeeding and hospitalization for diarrheal and respiratory infection in the United Kingdom Millennium Cohort Study. Pediatrics 2007; 119:e837-42.

21. Victora CG, Kirkwood BR, Ashworth A, Black RE, Rogers S, Sazawal S, et al. Potential interventions for the prevention of childhood pneumonia in developing countries: improving nutrition. Am J Clin Nutr 1999; 70:309-20.

22. Mahon BE, Ehrenstein V, Norgaard M, Pedersen L, Rothman KJ, Sorensen HT. Perinatal risk factors for hospitalization for pneumococcal disease in childhood: a population-based cohort study. Pediatrics 2007; 119:e804-12.

23. Rudan I, Boschi-Pinto C, Biloglav Z, Mulholland K, Campbell H. Epidemiology and etiology of childhood pneumonia. Bull World Health Organ 2008; 86:408-16.

Submitted on $02 / \mathrm{Feb} / 2009$

Final version resumitted on 19/Aug/2009

Approved on 22/Oct/2009 